\title{
On the Recyclability of Glass Fiber Reinforced Thermoset Polymeric Composites towards the Sustainability of Polymers' Industry
}

MCS Ribeiro ${ }^{1,2}$, ML Dinis $^{2,3^{*}}$, ACM Castro ${ }^{3,4}$, A Fiúza $^{2,3}$, AJM Ferreira $^{2}$, JP Meixedo $^{3,4}$ and MR Alvim ${ }^{4}$

${ }^{1}$ Institute of Science and Innovation in Mechanical and Industrial Engineering (INEGI), Rua Dr. Roberto Frias, Portugal

${ }^{2}$ Faculty of Engineering of University of Porto, Rua Dr. Roberto Frias, Portugal

${ }^{3}$ CERENA-Polo FEUP, Center for Natural Resources and the Environnent, Portugal

${ }^{4}$ School of Engineering of Polytechnic of Porto (ISEP), Rua Dr. Bernardino de Almeida, Portugal

\begin{abstract}
Considering the added value of recycling solution assessed by an evaluation of flexural and compressive loading capacity of PC specimens modified with mechanically recycled GFRP wastes, as well as the inherent environmental and economic benefits, the incorporation of GFRP recyclates into PC materials has been revealed as a viable technological option for the sustainability of the GFRP polymers' industry. Nevertheless, the recyclability of composite materials is complex and is sometimes seen as a key barrier to the adoption of these materials in some markets. One of the few successful applications, was developed by Reprocover, in Belgium, and it has been commercialized since 2011. In addition, the recently investigation line that was started and concerning the GFRP recyclates into PC materials also called the attention of Global Fiberglass SolutionsTM group. Even so, and although all the efforts that had been done on developing cost-effective recycling routes, GFRP wastes still remain mired by the scarceness of reliable outlet markets for the recyclates and clearly developed recycling paths between waste producers and potential consumers for the recyclates. However, it is foreseen that this scenario will change in the next few years as strong investments are being made in this field. The innovation in this field has just started, providing as this way a source of new opportunities.
\end{abstract}

Keywords: GFRP recyclates; Recycling; Sustainability; Composite materials; Polymers' industry

\section{Short Communication}

The production of glass fiber reinforced polymers (GFRP) has increased tremendously during the last decades. Their properties of lightness and high resistance, associated to a high resistance to corrosion, allow the application of these materials in a wide range of industries where significant problems of corrosion may occur, such as in the field of chemical industry. The attractiveness of these materials is also enhanced due to their high resistance/cost ratio and ability for application as structural elements in civil construction, transportation and automobile sectors [1].

Currently, most of the GFRP wastes are landfilled leading to significant negative environmental impacts. Thus, although the increasing use of thermoset composite materials, the recycling process of their by-products and end-of-lifecycle products comprises an important topic to consider. To reinforce this idea, one must take into consideration the fact that the European Commission directives are becoming more and more restrictive in this matter and the environmental issues posed by materials disposed in landfills is leading to an urgent reach of more industrial scale solutions to the recycling of composites [2]. In addition, with the new European Union's approach to waste management based on the "waste hierarchy", disposal (which includes landfilling and incineration without energy recovery) is the least preferred option while innovation in recycling is strongly encouraged [3].

The recyclability of thermoset composite materials is complex and is sometimes seen as a key barrier to the adoption of these materials in some markets. Typically, thermoset GFRP based products are considered demanding to recycle due to both cross-linked nature of thermoset resins, which cannot be remolded, and complex composition of the composite itself, which includes glass fibers, organic matrix and different types of inorganic fillers [4].
In the last decade, some recycling techniques have been proposed for GFRP waste materials: (a) incineration and co-incineration, with partial energy and raw materials recovery; (b) thermal and/or chemical recycling, such as solvolysis, pyrolysis and similar thermal decomposition processes, with fiber recovering; and (c) mechanical recycling or size reduction (with reduction to fibrous and/or powdered products) by grinding and milling processes. Thermal and/or chemical processes allow the recovery of fibers, but not always the recovery of valuable products from the resin (i.e. monomers that could be reused to produce resins). Additionally, the original resistance and length of recovering fibers is hardly achieved with these recycling processes. Mechanical recycling has important advantages over the previous ones: there is no atmospheric pollution by gas emission, a much simpler equipment is required as compared with ovens necessary for thermal recycling processes, and does not require the use of chemical solvents with subsequent environmental impacts [5].

The pressure on the development of new and economically viable markets for the recyclates, towards materials sustainability, have led over the last 20 years a relative great amount of research work on potential added value applications for GFRP waste recyclates. Mechanically, GFRP waste recycling is considered the most promising technique considering the feasibility of end-use applications. The most

*Corresponding author: Dinis ML, Faculty of Engineering of University of Porto, Rua Dr. Roberto Frias, Portugal, Tel: +351 225081430; E-mail: mldinis@fe.up.pt

Received September 12, 2016; Accepted September 21, 2016; Published September 28, 2016

Citation: Ribeiro MCS, Dinis ML, Castro ACM, Fiúza A, Ferreira AJM, et al. (2016) On the Recyclability of Glass Fiber Reinforced Thermoset Polymeric Composites towards the Sustainability of Polymers' Industry. Int J Waste Resour 6: 250. doi: 10.4172/2252-5211.1000250

Copyright: (c) 2016 Ribeiro MCS, et al. This is an open-access article distributed under the terms of the Creative Commons Attribution License, which permits unrestricted use, distribution, and reproduction in any medium, provided the original author and source are credited. 
Citation: Ribeiro MCS, Dinis ML, Castro ACM, Fiúza A, Ferreira AJM, et al. (2016) On the Recyclability of Glass Fiber Reinforced Thermoset Polymeric Composites towards the Sustainability of Polymers' Industry. Int J Waste Resour 6: 250. doi: 10.4172/2252-5211.1000250

Page 2 of 2

extensive research work has been carried out on Portland cement concrete, in which grinded GFRP waste scrap has been incorporated either as reinforcement, aggregate or filler replacement [6]. These enduse applications bring however, depending upon glass fiber nature, some incompatibility problems arisen from alkalis silica reaction (ASR). This drawback, brought by cementious binder matrix, could be avoided using as host material a cementless concrete like polymer based concrete (PC) materials. PC materials are high performance resin based concretes, in which a polymer acts as binder matrix for the mineral aggregates. High strength to weight ratio, improved resistance to chemical and frost attack, very fast curing and excellent bond to several substrates, are the main advantages of these materials over cement based concretes [7]. Moreover, due to hermetic nature of resin matrix, polymer concrete and mortar composites present a great ability for incorporating recycled waste materials either industrial by-products or end-life products. Recycling and waste encapsulation constitutes nowadays the new and emerging branch market for PCs. Regardless of the relative large amount of research work undertaken on the incorporation of recycled wastes in polymer based concretes, until now, few studies have focused on the incorporation of GFRP recyclates into PCs [5,8-12]. The outputs of these few research works have highlighted the added value of this recycling solution, revealing that the incorporation of mechanically recycled GFRP wastes into PC materials is a viable technological option for the sustainability of the GFRP composite materials' industry [5,8-12].

Although the recycling of GFRP composite materials is moving towards on the right direction focusing on the sustainability of polymers' industry, there are many challenges that still have to be takenup to develop a real consuming market. The intended perspectives for final applications of concrete and/or composite materials modified with GFRP recyclates include, among others, moulding compounds, precast slabs, paving blocks, railroad sleepers, wall panels, manhole covers, valve chambers, cement floor screeds, valley gutters, roofing sheet and flat sheets for signage; however, only few of these products came out of the investigation field and had an industrialized expression. One of the few successful applications (manhole covers, utility boxes and urban furniture made of thermoset and glass fibre flakes wastes aggregated in a resin under high pressure cold moulding), was developed by Reprocover, in Belgium, and it has been commercialized since 2011 [13]. Nevertheless, apart from some in-house recycling (such as the above example), attempts to commercialize these products as a recycling route for GFRP wastes have failed.

Regarding GFRP recyclates into PC materials, recently, this investigation line that was started by Ribeiro et al. [12], also called the attention of Global Fiberglass SolutionsTM group. Over the last three years, this company has invested significant efforts on research and product development, and expect to commercialize final precast products for rail and roadways infrastructures under the trademark of 'Ecopolycrete' [13]. Even so, and although all the efforts that had been done on developing cost-effective recycling routes, GFRP wastes still remain mired by the scarceness of reliable outlet markets

Citation: Ribeiro MCS, Dinis ML, Castro ACM, Fiúza A, Ferreira AJM, et al. (2016) On the Recyclability of Glass Fiber Reinforced Thermoset Polymeric Composites towards the Sustainability of Polymers' Industry. Int J Waste Resour 6: 250. doi: 10.4172/2252-5211.1000250 for the recyclates and clearly developed recycling paths (logistics, infrastructures and recycling facilities) between waste producers and potential consumers for the recyclates. However, it is foreseen that this scenario will change in the next few years as strong investments are being made in this field. The innovation in this field has just started, providing as this way a source of new opportunities.

\section{References}

1. Conroy A, Halliwell S, Reynolds T (2006) Composite recycling in the construction industry. Composites Part A: Applied Science and Technology 37: 1216-1222.

2. Geraldine O, Dandy LO, Leeke GA (2015) Current status of recycling of fibre reinforced polymers: Review of technologies, reuse and resulting properties. Progress in Materials Science 72: 61-99.

3. EuCIA-European Composites Industry Association, Composites Market Report 2015: Market developments, trends, challenges and opportunities.

4. Pimenta S, Pinho ST (2011) Recycling carbon fibre reinforced polymers for structural applications: Technology review and market outlook. Waste Management 31: 378-392.

5. Ribeiro MCS, Fiúza A, Ferreira A, Dinis ML, Castro ACM, et al. (2016) Recycling Approach towards Sustainability. Advance of Composite Materials' Industry, Recycling 1: 178-193.

6. Ribeiro MCS, Fiúza A, Ferreira AJM (2016) Recycling and Reuse of Fiber Reinforced Polymer Wastes in Concrete Composite Materials.

7. Fowler DW (1999) Polymers in concrete: A vision for the 21st century. Cement and Concrete Composites 21: 449-452.

8. Castro ACM, Carvalho JP, Ribeiro MCS, Meixedo JP, Silva FJG, et al. (2014 An integrated recycling approach for GFRP pultrusion wastes: recycling and reuse assessment into new composite materials using Fuzzy Boolean Nets. Journal of Cleaner Production 66: 420-430.

9. Castro ACM, Ribeiro MCS, Santos J, Meixedo JP, Silva FJG, et al. (2013) Sustainable waste recycling solution for the glass fibre reinforced polyme composite materials industry. Construction and Building Materials 45: 87-94.

10. Ribeiro MCS, Fiúza A, Castro ACM, Silva FG, Dinis ML, et al. (2013) Mix design process of polyester polymer mortars modified with recycled GFRP waste materials. Composite Structures 105: 300-310.

11. Ribeiro MCS, Fiúza A, Castro ACM, Silva FJG, Meixedo JP, et al. (2011) Recycling of Pultrusion Production Waste into Innovative Concrete-Polymer Composite Solutions. Advanced Materials Research 295: 561-565.

12. Ribeiro M, Meixedo JP, Fiúza A, Dinis, ML, Castro ACM, et al. (2011) Mechanical Behaviour Analysis of Polyester Polymer Mortars Modified with Recycled GFRP Waste Material. World Academy of Science, Engineering and Technology 75: 365-371

13. Job S (2014) Recycling composites commercially. Reinforced Plastics 58: $32-38$

\section{OMICS International: Open Access Publication Benefits \&} Features

Unique features:

- Increased global visibility of articles through worldwide distribution and indexing

- Showcasing recent research output in a timely and updated manner

- Special issues on the current trends of scientific research

Special features:

$700+$ Open Access Journal

$50,000+$ editorial team

Rapid review process

Quality and quick editorial, review and publication processing

Indexing at major indexing services

Sharing Option: Social Networking Enabled

Authors, Reviewers and Editors rewarded with online Scientific Credits

Better discount for your subsequent

Submit your manuscript at: www.omicsonline.org/submission 